\title{
Teaching and Learning about Writing Abstracts: Viable Tools to Kick-Start a Research Activity
}

\author{
Kola O. Odeku \\ Faculty of Management and Law, School of Law, \\ University of Limpopo, South Africa \\ E-mail:kooacademics@gmail.com
}

\section{Doi:10.5901/mjss.2014.v5n3p678}

\section{Abstract}

In virtually all research works undertaken, an abstract of the work is required as a starting point before the research work is written out in details. Abstract mirrors what is expected to be found in the main work. It is a summary of the whole work written in 250 to 350 words depending on the house style or requirement of the journal or the institution that it will be submitted to. In most cases, before a full paper is submitted for a review, editors usually require that an abstract of the paper should be written and submitted for purposes of adjudication in order to know whether the topic being researched falls within the themes and ambits of the journal or conference. Against this backdrop, many abstracts have been rejected due to insufficient and shallow information presented in the abstract. Sometimes, the abstract written will be at variance with the topic thereby creating confusion. For these reasons and other reasons that will unfold in this article, some abstracts have been rejected and this has halted the possibility of a researcher progressing with the research works. This paper explains how to write an acceptable abstract and the components thereof.

Keywords: Components of an abstract, errors, adjudication, journals, dissertations and thesis

\section{Introduction}

These days, in most of the research works, particularly published article in journals, "the abstract' containing the main idea of the article is written immediately after the title (Bell, 2010). An abstract is described in the Oxford Advanced Dictionary as "a short piece of writing containing the main ideas in a document." However, it is pertinent to mention that an abstract can be written from the perspectives of the nature of research or study to be undertaken (Rossman and Rallis, 2011). Abstract of research based on quantitative research method should provide the highlights on the introduction, methods, results, discussion and conclusions (Flick, 2014). The abstract of research based solely on qualitative research and method whereby the study relies mainly on literature and existing information should provide the introduction, the problem identified and the use of literature to solve the problem (Kothari, 2004). While quantitative research method is peculiar to the science and humanities disciplines (Silverman, 2013), qualitative research method is widely used by arts and law disciplines to conduct research and findings (Jupp, 2006). Qualitative research method is prominent in the legal research; however, some legal researches use the blend of qualitative and quantitative methods (Spencer and Britain, 2003). What is important is that, from the outset in the abstract, the author should disclose the methodology depending on the writing style. Explaining the unique features of qualitative research, Rossman and Rallis (2011:6) wrote "the research is the means through which a study is conducted, and the purpose is to learn about some facets of the social world. Both of these characteristics are integrated to a view of learning that sees the learner as a constructor of knowledge rather than a receiver. From this perspective, data-not reality itself but rather representations of reality is accumulated. These data are then transformed through analysis and interpretation into information which when put to practical use become knowledge."

A notable description of what an abstract entails is well captured by Kotze (2007) thus "an abstract it is a short summary with a maximum length of 200-250 word. Most readers first scan the abstract in order to decide whether reading the rest of the article would be worthwhile. The abstract, therefore, serves as an important "window display" or "advertisement" for your work and provides an opportunity to impress the reader."(Kotze, 2007).

Therefore, an abstract talks to a specific problem and also indicates how the problem will be solved and the method to be used to solve it (Roschelle and Teasley, 1995). It is a roadmap; it describes how the journey will begin and where it will end (Bloomberg and Volpe, 2012). What makes this article unique and important is that it explains how law 
researchers can effectively write an acceptable abstract before a full blown article is written and submitted for consideration for publication. This is against the backdrop that those who are new to the legal research have become disillusioned and suffered major setback permanently as a result of their abstracts being rejected by reviewers and editors therefore making them to be disinterested in research.

The importance of an abstract is numerous especially with regard to scholarly works for either presentation at conferences or for a research thesis and dissertations (Cooper, 1998). In most institutions of higher learning, for a lecturer to seek permission to attend a conference, one of the requirements is a letter of acceptance of the abstract of the paper to be submitted subsequently. With the acceptance letter evidencing that the abstract has been accepted for presentation at the conference, the lecturer may then apply for leave of absence to attend the conference. Most Universities will not approve a leave of absence for a lecturer to attend a conference if there is no evidence of acceptance of abstract of the paper to be read at the conference.

If the abstract is accepted, there is every likelihood for it to be published by the conference organisers in the book of abstract. To some extent, the abstract can be referred to and cited. The published article forms part of academic works of the author and can be used for other academic purposes.

Similarly, majority of the higher institutions require that while submitting a research document at the post graduate level, the student has to provide an abstract. The abstract forms part of the research output and serves as a summary of the whole document. Pursuant to this, it must be written in order to grab the attention of the reader and at the same time capture the whole issues raised and discussed in the research thesis or dissertation.

Therefore, an abstract is used to communicate the findings of the whole research work (Dos Santos, 1996).

\section{Literature Review}

Robert and Fletcher (1998:607) assert that "abstracts are often the earliest form in which new scientific research works are made available, the only form in which researches are presented, or the only part of an article that is read." The implication of what Robert and Fletcher want us to bear in mind is that, author should write a very good abstract that contains all the relevant information pertaining to the subject being addressed or the main text.. Readers will, usually read the abstract to see whether it contains interesting issues that will warrant reading the text itself. It should also be pointed out that most readers only go through abstracts and from the retrieve information they require without going through the main text (Ritchie et al, 2003).

Kintsch (1974) describes an abstract as "a series of empirical and theoretical investigations of the role of meaning in psychological processes. A theory is proposed for the representation of the meaning of texts that uses ordered lists of propositions. Topics include the role of lexical decomposition in comprehension and memory and propositions as the units of recall." (Kintsch,1974).

According to Pierson and Faarc (2004:1206) "Preparation, submission, and presentation of an abstract are important facets of the research process, which benefit the investigator/author in several ways. Writing an abstract consists primarily of answering the questions, "Why did you start?" "What did you do?" "What did you find?" and "What does it mean?" An author can easily write an abstract by providing answers to these questions. This is one style of writing an abstract. The type of the research being conducted will usually inform how the abstract will be written. This makes writing of an abstract very dynamic however, it differs from one discipline from another but still contains the essential elements that are generally acceptable in any abstract (Scardamalia and Bereiter, 2006). While scientific research will talk about the primary data, legal research will mention reliance on literature to solve the problem (Ary et al, 2010).

Robert and Fletcher (1998:607) indicate that abstracts of published manuscripts are brief summaries of the work, printed at the beginning of the article...other abstracts, usually somewhat longer...more informative abstract is longer and more explicit structured." While Robert and Fletcher's perspective is valid, it is pertinent to point out that the author has to structure the abstract in accordance with the house style of the journal. If the journal requires 250 words for an abstract, the author must confine the writing within the stipulated words. The implication of this is that the author should have first-hand information about the requirement of the journal before sending an abstract or the paper otherwise, it may be rejected.

Writing an abstract also entails subjecting the abstract to peer review in order to ensure that it discloses researchable issues and what gap needs to be filled (Squires, 1990). 


\section{The Components of an Abstract}

An abstract should be written clearly and concisely and it should disclose the key issues to be discussed in the main text (Pierson and Faarc, 2004). Pierson and Faarc (2004) described an abstract as "a condensed version of a full scientific paper, it describes a study and its results. It is a means of conveying to one's peers what was done, why it was done, what was found and what the implications are. Because it is strictly limited, either in the number of words it can contain or in the space it can occupy on a page, an abstract can be only a "bare bones" version of all the information pertaining to the study."

An abstract provides an insight into what the whole article is all about (Pentland, 1999). It gives first-hand information on what is to be expected. Abstract in itself is not the main article but a summary of the whole article written in about 200 to 500 words.

A well written abstract that provides concrete information makes a positive impression on the readers and get them excited about the work (Feldman, 2004). This will arouse the appetite and interest of the readers and they will want to go further in order to dig deeper into the work because he or she already has that strong belief that knowledge has been constructed and produced which will eventually lead to learning new things in the area researched (Elbow, 1998). Depending on the discipline and areas of interest, an abstract should be written in such a way to meet the requirement of the discipline (Shih, 1986). For an example, in law, the scientific way of conducting legal research is purely by relying on secondary data/information (Collecchia, 2013). This information will then be processed through analysis, examination, interrogation and criticisms in order to construct new knowledge in the field. This is acceptable in legal research. However, it should be pointed out that if quantitative research approach is to be used in legal research, it has to follow the laid down rules governing the method. The focus of this paper is therefore to confine discussion qualitative legal research approach for purposes of writing an abstract.

Some researchers have offered useful suggestions on what a good abstract should contain. Perry et al (2003:653) provide very useful and meaningful insights. They recommended that a good abstract should contain these seven elements:

First, an abstract should begin with a brief description of what issues the article will address. The description should be scholarly and couched in such a way that it will appeal to and attract the attention of the readers. Secondly, an abstract should disclose in clear words the aim or purpose of the study. Thirdly, the problem identified and the need to intervene in order to construct new knowledge should be well articulated. Fourthly, a brief description of the methodology and how the article would be written should be briefly explained. Fifthly, the findings of the study should be well stated because these are the key and concrete evidence of the new knowledge constructed and produced. Sixthly, the concluding part should provide an insight on how the study has been able to solve the problem and the new knowledge produced. Lastly, recommendations are very essential. The abstract should briefly state what the author recommends and the areas for further research.

A hypothetical example of a written abstract that incorporated the seven elements is given thus:

"Abstract The purpose of this paper is to explain the similarities and differences between Climate Law and Environmental Law in order to improve understanding of the concepts. Although these concepts cannot be studied separately, they are not completely the same. Thus finding conceptual connotations behind both concepts are sine qua non for unravelling the difficulties bedevilling enforcement and implementation of laws protecting the environment. Given that Climate Law and Environmental law have already met with serious opposition regarding its implementation in many developed countries of the world, it has become pertinent to explore deeper meanings into the laws that are meant to protect the environment and the atmosphere. Doing so requires an in-depth research into the contemporary understanding of the concepts of environmental law and climate law as opposed to the general perception that they mean one and the same thing at all times. Finally this paper suggests a balanced and conceptual approach to the interpretation of environmental law. It is hoped that this paper would provoke further critical debate in environmental lawmaking and a better informed public participation in the issues of climate change."(Odozor and Odeku, 2014).

Explanations of the elements in the example above are:

i. Element 1. The paper abstract presents the issue to be addressed namely "the similarities and differences between Climate Law and Environmental Law in order to improve understanding of the concepts." (Odozor and Odeku, 2014).

ii. Element 2. From the beginning, the abstract stipulates the purpose and reason for the paper thus "The purpose of this paper is to explain the similarities and differences between Climate Law and Environmental Law in order to improve understanding of the concepts. Although these concepts cannot be studied 
separately, they are not completely the same." (Odozor and Odeku, 2014).

iii. Element 3. The problem identified "Given that Climate Law and Environmental law have already met with serious opposition regarding its implementation in many developed countries of the world, it has become pertinent to explore deeper meanings into the laws that are meant to protect the environment and the atmosphere." (Odozor and Odeku, 2014).

iv. Element 4. The methodology for the study is well articulated thus "Doing so requires an in-depth research into the contemporary understanding of the concepts of environmental law and climate law as opposed to the general perception that they mean one and the same thing at all times." (Odozor and Odeku, 2014).

v. Element 5. The abstract reveals what the findings are "Thus finding conceptual connotations behind both concepts are sine qua non for unravelling the difficulties bedevilling enforcement and implementation of laws protecting the environment."

vi. Element 6. In conclusion, the abstract points out that "Finally this paper suggests a balanced and conceptual approach to the interpretation of environmental law." (Odozor and Odeku, 2014).

vii. Element 7. Recommendations are very significant in legal research approach. This will serve as a platform for further interrogation of the areas not covered by the study. More importantly, using a comparative study, it also serve as a platform for the author to come up with reforms of the existing law in order to strengthen it. This is presented thus "It is hoped that this paper would provoke further critical debate in environmental law-making and a better informed public participation in the issues of climate change." (Odozor and Odeku, 2014).

\section{Other Useful Hints}

a) It must be borne in mind that an abstract is a resume of the whole article and as such, all vital issues raised in the abstract must be thoroughly canvassed in the main text. In other words, all points and issues raised in the abstract have to be critically analysed in the text in order to fill the gap identified and solve the problem.

b) Beginners or new academic members should try as much as possible to write their abstracts under the guidance of experienced mentors (Robert and Fletcher, 1998).

c) No matter how brilliant an abstract is written, it will remain an abstract and cannot amount to or be equivalent to an introduction in an article or document. Therefore, after an abstract is written, introduction should follow. An introduction provides an idea of what the study is about and the reason why the study is undertaken. It also states the hypothesis and what is set out to be achieved and the benefits. According to Feldman (2004:2) "the main function of the introduction is to provide readers with a funneling framework: the general nature of the management problem being investigated, previous research on the management issue, and how your paper fills some niche or gap in that literature."

d) An abstract should contain full information of the issues to be addressed but should be brief and concise.

e) As indicated in (a) above that an abstract is a summary of the whole article, consequently it should not contain or reflect the following: figures to be used in the main article, tables, diagrams, pictures, references, sources and so on. Fortunately, in legal research, researchers rely hugely on literature as data, hence there is mostly no need to make use of figures and so on.

f) More importantly, the abstract must be subjected to scrutiny and peer review before it is finally submitted. This will give neutral and independent minds the opportunity to assess the authenticity of the study that has been done. It also gives the reviewer the opportunity to consider whether the study will construct and produce new knowledge.

g) Ensure that the abstract is written to meet the requirement of the journal. For instance, if it says 200 words, adhere to 200 words. Exceeding the words stipulated can irritate the reviewers and the rejection of the abstract can result to delay in the acceptance of the paper.

\section{Challenges and Interventions}

Writing an abstract, particularly an acceptable abstract is a daunting work (Wood and Morrison, 2011). The major challenge usually faced by authors is how to establish priorities for what can be included or omitted in an abstract that requires about 200 words. Sometimes, it takes quite an ample time especially when one is a beginner (Robert and Fletcher, 1998). While it is easier for an experienced established researcher to write an acceptable abstract, a beginner might not possess such skill, hence the need for an experienced author mentor to provide assistance in form of guiding 
and mentoring the beginner by scrutinising and offering useful comments on abstracts written by the beginners (GalvezHjornevik, 1985). Writing an acceptable abstract is a learning curve and the beginner must be ready to go through the process in order to be able to grapple with the nitty-gritty of how to write an acceptable abstract (Franklin, 2012).

Writing an abstract requires extensive reading in order to grapple with the area being researched and find out the gaps in the literature before attempting to fill the gaps (Golden-Biddle and Locke, 2007). It also requires compressing the relevant information gathered over lengthy readings and couch them in simple sentence that will communicate to the reader (Berg and Lune, 2004). In the process, sometimes, the author will omit vital details that took ample time and human effort to source and acquired. This notwithstanding the author still needs to ensure that the abstract is written to meet the requirement for it to be well articulated and acceptable. Therefore, it is incumbent on the author to make sure that the content is concise yet robust in order for it to stand out. This is pointed out against the backdrop that there are many abstracts that have written and submitted to conferences or journals but rejected due to no-compliance or grammatical errors. At this point, it is pertinent to echo what Cartwright et al (2010) said on difficulty that are usually encountered by non-English speakers and offered an advice on enlisting the services of professional proof-readers to do the needful thus "Drafting a clearly worded, readable abstract is difficult even for native English speakers. While spelling errors and solecisms will not rule out acceptance of high quality science, there is evidence that reviewers are biased in favour of well-written abstracts. Non-native English speakers should therefore enlist native English speakers or better still, professional ... writers to review their drafts."

During adjudication by the members of a scientific committee, they tend to accept abstract that is well -written I in view of the fact that they have several to adjudicate and have no luxury of time to try to make sense out of an abstract that is badly written.

An abstract will fall short of a good abstract if it is badly written or presents general information without telling the readers what the problem, the aim and objective and how the problem will be solved. Feldman (2004:2) describes a badly written abstract like this "the number one problem with badly written abstracts is too much approach andnot enough arrival. Sometimes abstracts are so generically written that they do not pique the reviewers' interest at all. Many read like this: "Topic A is increasingly important in the global marketplace. Drawing upon the literatures in B, C, D, and E, we present a general framework for understanding A. Data were collected from a wide variety of firms and several interesting patterns of findings emerged. The article concludes with a discussion of future research directions and implications for management practice."

To avoid what Feldman described as badly written abstract, authors should bear in mind that abstracts are their first chance to make a positive impression on reviewers; try to give the readers some concrete information to get them excited about the work. While writing an abstract, the details should be presented succinctly but briefly. There is no hard and fast rule on the length of an abstract; however, the general consensus seems to be that it should be in the neighbourhood of 25- to 350 words (Feldman, 2004).

At all times, the author needs to ensure that the abstract contains essential information while weeding out as much as possible, materials and information that have no significance or are of lower priorities from the abstract.

Consequently, an abstract should be well-written and contain the essential elements that are supposed to be included in the abstract. In so doing, it will be a viable step to writing very good and acceptable abstract. Writing of a good abstract is not a matter of how much work the author has put into it or the display of knowledge but how well the abstract is written that will make it attractive and catch the attention and interest of the reader.

\section{Conclusion}

Tutoring on how to write an acceptable abstract is desirable and formidable as an essential part of mentorship, however, practice through writing is a must for students and academics. Abstract is now part of components of any scholarly works. In most cases, it is mandatory. It gives an insight into what the whole research study is all about. It summarises the whole document in simple language by bringing out the essential issues canvassed and how they were solved. It differs from one disciple to another but the line of difference is very thin. Virtually all abstracts contain the same elements and the characteristics are universal in structure.

\section{Recommendations}

The only way to write an acceptable abstract is through intensive reading and practice. For beginners, it is recommended that authors should read quite a number of well written abstracts published in scholarly journals and books. 
Mentorship is also very vital. Beginners and learners in writing articles for publishing should tap into the wealth of experience of contemporary scholars to provide guidance and assistance.

Rejection of an abstract at the first instance should not deter an author. As a matter of fact, the rejection should propel and stimulate the drive in the author to know why the abstract was rejected and what correction and improvement should be done to make it acceptable and publishable.

\section{References}

Ary D, Jacobs LC, Razavieh A, Sorensen C 2010. Introduction to research in education, Wordsworth Cengage Learning, Belmont, USA. Bell J 2010. Doing your research project, Open University Press, Berkshire, UK.

Berg BL, Lune H 2004. Qualitative research methods for the social sciences. From ftp://174.46.176.136/Pearson/9780205809387.pdf. (Retrieved February 16, 2014).

Bloomberg LD, Volpe M, 2012. Completing Your Qualitative Dissertation: A Road Map From Beginning to End: A Road Map From Beginning to End, Sage Publication, California, USA.

Cartwright R, Kari A O, Tikkinen ME, Vierhout HK 2010. How to write an ICS/IUGA conference abstract, International Urogynecol Journal, 21:509-513.

Collecchia L 2013. Law as Information Processes. From http://hdl.handle.net/1807/42756. (Retrieved March 1, 2014).

Cooper HM 1998. Synthesizing research: A guide for literature reviews, Sage Publication, London, UK.

Dos Santos MB 1996. The textual organization of research paper abstracts in applied linguistics, An Interdisciplinary Journal of Language, Discourse \& Communication Studies, 16(4):481-499.

Elbow P 1998. Writing with power: Techniques for mastering the writing process, Oxford University Press, New York, USA.

Feldman DC 2004. The Devil is in the Details: Converting Good Research into Publishable Articles Daniel C. Feldman, Journal of Management February, 30(1):1-6.

Flick U 2014. An introduction to qualitative research, Sage Publication, London, UK.

Franklin MI 2012. Understanding Research, Routledge, NY, USA.

Galvez-Hjornevik C 1985. Mentoring: A Review of the Literature with a Focus on Teaching. From http://files.eric.ed.gov/fulltext/ED262032.pdf. (Retrieved March 4, 2014).

Golden-Biddle K, Locke K 2007. Composing qualitative research, Sage Publication, California, USA.

Jupp V 2006. The Sage dictionary of social research methods, Sage Publications Ltd, London, UK.

Kintsch W 1974. The representation of meaning in memory, Oxford, England: Lawrence Erlbaum, pp. 279.

Kothari CR 2004. Research methodology: methods and techniques, New Age International, (P) Ltd, Publishers, New Delhi, India.

Kotze T 2007. Guidelines on writing a first quantitative academic article. From http://cs.hope.ac.uk/courses/comms/assessments Iwriting_an_academic_journal_article.pdf. (Retrieved February 9, 2014).

M Scardamalia, C Bereiter 2006. Knowledge building: Theory, pedagogy, and technology, The Cambridge handbook of the learning, London, UK.

Odozor C, Odeku KO 2014. Explaining the Similarities and Differences between Climate Law and Environmental Law, Journal of Human Ecology, 45(2): 127-136.

Pentland BT 1999. Building process theory with narrative: From description to explanation, Academy of management Review, 24(4):711-724

Perry C, Carson D, Gilmore A 2003. Joining a conversation: Writing foe EJM's editors, reviewers and readers require planning, care and persistence, European Journal of Marketing, 37(5/6):652-657.

Pierson DJ, Faarc MD 2004. How to Write an Abstract That Will Be Accepted for Presentation at a National Meeting, Respiratory Care, 49(10):1206-1212.

Ritchie J, Spencer L, O'Connor W, 2003. Carrying out qualitative analysis, Sage Publication, New Delhi, India.

Robert H, Fletcher MD 1998. Writing an abstract, Journal of General Internal Medicine, 3(6): 607-609.

Roschelle J, Teasley SD 1995. The Construction of Shared Knowledge in Collaborative Problem Solving, Computer Supported Collaborative Learning, 128: 69-97

Rossman GB, Rallis SF, 2011. Learning in the field: An introduction to qualitative research, Sage Publication, California, USA.

Rossman GB, Rallis SF 2011. Learning in the field: An introduction to qualitative research, Sage Publication, California, USA.

Shih M 1986. Content-Based Approaches to Teaching Academic Writing, MAY SHIH TESOL Quarterly, 20(4): 617-648.

Silverman D 2013. Doing qualitative research: A practical handbook, Sage Publications Ltd, London, UK.

Spencer L, Britain G 2003. Quality in Qualitative Evaluation: A framework for assessing research evidence. From http://www.policyhub.gov.uk/docs/qqe_rep.pdf. (Retrieved February 19, 2014).

Squires BP 1990. Structured abstracts of original research and review articles, Canadian Medical Association Journal, 143(7): 619-622.

Wood GH, Morrison RS 2011. Writing abstracts and developing posters for national meetings, Journal of palliative medicine, 14(3): 353359. 